\title{
Situation Management of Agricultural Production Based on the Prediction of Prices for Agricultural Products
}

\author{
Marina Polkovskaya \\ Irkutsk State Agrarian University named after A.A. Ezhevsky \\ Irkutsk, Russia \\ polk_mn@mail.ru
}

\begin{abstract}
There were analyzed the main global and Russian trends of agricultural prices in this article. According to the mathematical model "Cassandra", were allocated a trend, a seasonal component and a remainder term of a series of average monthly prices for various agricultural products in the Irkutsk region for 2012-2017. At the same time, the relationship between the components of the obtained models is additive. By using models taking into account seasonality, the predicted values of the parameter under study for 2018 were calculated. The price values were used to solve the problem of optimizing agricultural production for JSC "Irkutsk seeds" in the Irkutsk region. According to obtained results, the smallest profit will be received from the sale of manufactured products in October, and the largest - in July. For a more accurate calculation of profits in the sale of products at the most favorable prices, an optimization task requires the introduction of additional parameters taking into account storage costs, storage capacity, product losses, etc. The received results of the analysis of food prices excreting seasonal component and their use in mathematical programming problems can be used by agricultural producers in the planning of production.
\end{abstract}

Keywords - price forecasting, trend, seasonal component estimation, situational management, parametric programming problem

\section{INTRODUCTION}

Traditionally, prices for various types of products are set by sellers, and buyers react to prices; the price level is determined at the cross point of supply and demand. The cost of goods depends on various factors, as economic (value of costs, production volumes, quality, competition, demand, etc.) so social (political situation in the country, perceived value, etc.). At the same time, prices for the same type of agricultural products for different buyers (the state, processing companies, wholesale, retail) may differ significantly. Seasonal effects have a significant impact on the pricing of agricultural products. If prices for products of the livestock industry (milk, meat, eggs) slightly change under the influence of seasonality, then prices for products of the crop industry during the harvest period may not only fall significantly, but also rise significantly. In lean years there is an increase in prices, and in years with high yields - a decrease. Besides yield, which depends mainly on climatic parameters, also world market prices, availability of stocks, oil prices, exchange rates, etc. have impact on price level on agriculture products. In assessing price movements, it is of interest not only to forecast them for the short and long term, but also to use the obtained results to control agricultural production.

In accordance with the purpose the following tasks are formulated:

- assessment of world and Russian prices for agricultural products;

- allocation of the trend, seasonal component and residual component in the series of average monthly consumer prices in the Irkutsk region;

- the use of forecast values of prices in the planning of agricultural production.

\section{RESEARCH METHODS AND MATERIALS}

For selection of trend, seasonal component and remainder term series of prices was used the mathematical model "Cassandra" $[4,5]$. The prices of wheat, vegetables, milk and meat of different countries (Canada, China, Germany, Russia, USA) are taken as initial data for the analysis of world trends. In forecasting, the series of average monthly consumer prices for the Irkutsk region for 2012-2017 (rubles per ton) of the following products were used: wheat, legumes, potatoes, seeds of perennial grasses for hay, pork in live weight. The task of optimizing the production of agricultural products is implemented on the example of the agricultural enterprise JSC "Irkutsk seeds" of the Irkutsk region with the help of linear programming methods.

\section{RESULTS}

\section{A. Assessment of world and Russian prices for agricultural products}

According to many experts and scientists, the state of agriculture in Russia, the situation on the agricultural market, and therefore the food security of our country are in critical condition [6]. Despite the adopted strategy of import substitution and development of the agricultural sector, agricultural production in Russia lags far behind the developed countries of the world. In particular, the share of total 
agricultural support in gross value added in Russia is 1.5-2 times lower than in the EU and the USA [7].

In addition, the prices of many agricultural products imported and exported by Russia often depend on the level of prices on the world market.

The paper analyzes the prices of various agricultural products of crop production (wheat, carrots, potatoes, cucumbers) and livestock (beef, chicken, pork, milk) for 2010-2017 in Canada, China, Germany, Russia, USA [8]. Since the statistics are presented in different currencies, the actual prices have been translated into relative prices by dividing by the average of the multi-year series for 2010-2017. Due to the lack of information on prices for some years, there are gaps in the charts.
Wheat prices in the studied countries at different times have a deviation of $\pm 50 \%$ relative to the average value. At the same time, the growth of prices in most countries was observed from July to December 2012, then there was a smooth decline. Currently, this indicator is at the level of the average value. In Russia, high grain prices were also observed in 2015 and early 2016, due to limited grain reserves and high demand in the domestic and foreign markets.

According to figure 1, the prices of cucumbers in China and Russia have a pronounced seasonal wave, the price rises in the winter, when these products are produced in smaller volumes, and decreases in the summer. At the same time, the prices of this type of products of other countries change randomly.

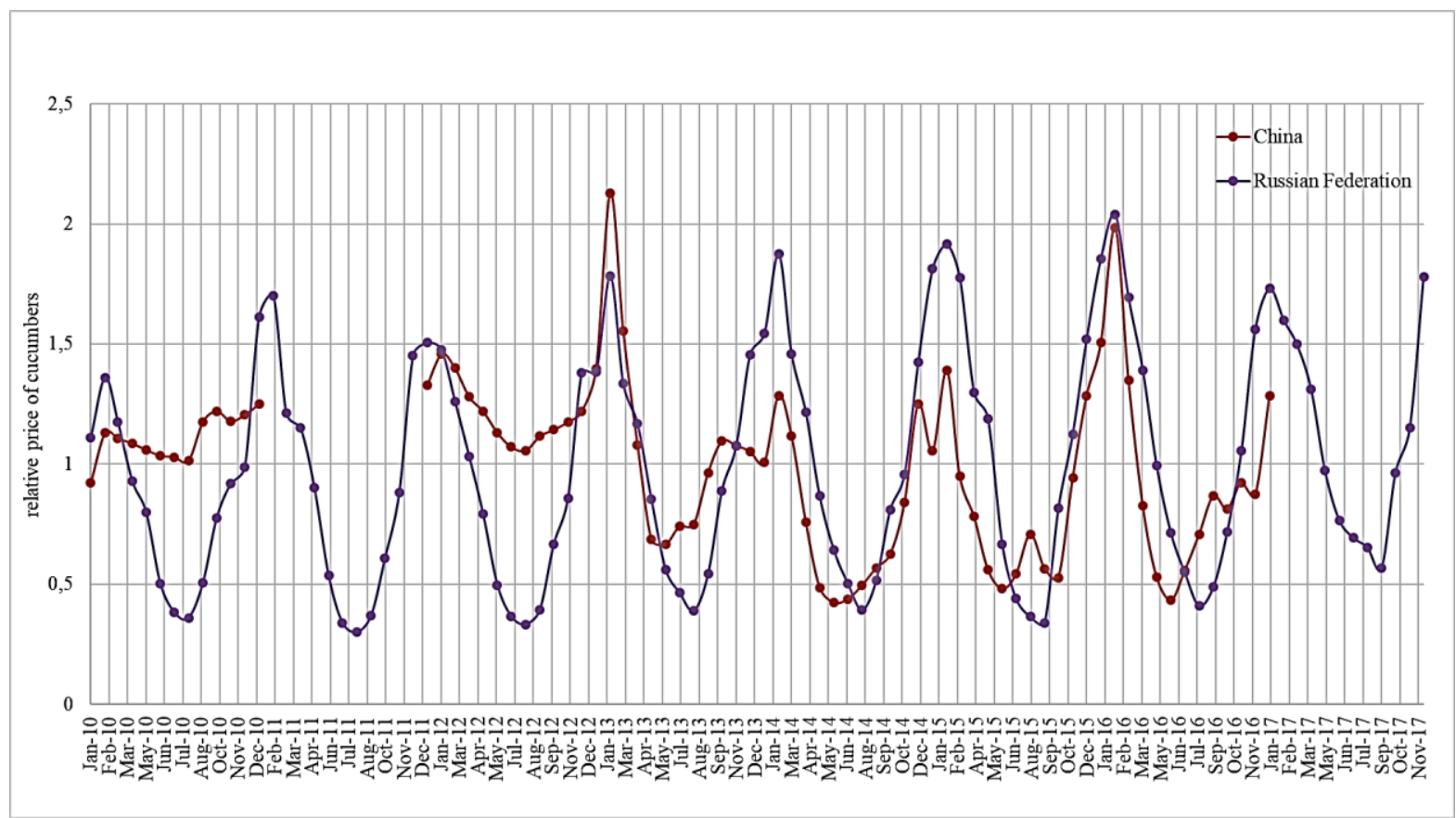

Fig. 1. Average monthly prices of cucumbers for 2010-2017 in different countries, calculated by dividing by average values

In the ranks of prices for carrots and potatoes, the seasonal wave is less clear. However, there is a logical pattern - the lowest price for these products in the fall (mainly in October), and high - in the spring and summer. The maximum deviation of the price of carrots from the average value of the long-term series was recorded in June 2015 in Russia and amounted to 3.3. For potatoes the figure is changed in the range of 0.44 to 1.8 .

Prices for beef, pork and chicken during the study period increased by about 1.5-2 times. At the same time, prices behave differently in different years. The seasonal wave is weakly expressed or absent. A significant increase in the price of beef was noted in 2014 - early 2015 in Canada and the United States; pork - in early 2014 in the United States.

As for milk prices, in Canada and China, they have not changed during the study period. In Germany, the maximum deviations from the mean were 0.7 and 1.3. In a long-term series of average monthly milk prices in the US, not only the seasonal wave is visually determined, but also the presence of other factors that affect the price change. In addition, attention is drawn to the trend of price growth from 2010 to 2014 and its further decline. The linear trend is obtained for the studied parameter according to the Russian data: $\mathrm{y}_{\mathrm{t}}=$ $0.0003 \mathrm{t}-9.70$, the coefficient of determination is close to $\mathrm{R}^{2}=0.91$. As can be seen from figure 2 , there is a clear seasonal wave that characterizes the price increase in the autumn-winter period, and the decrease - in the spring-summer.

It should be noted that most of the countries under consideration have a subtropical and continental (moderately continental) climate, including the European part of Russia. These types of climate are suitable for growing various crops (grains and vegetables) and livestock (milk and meat). 


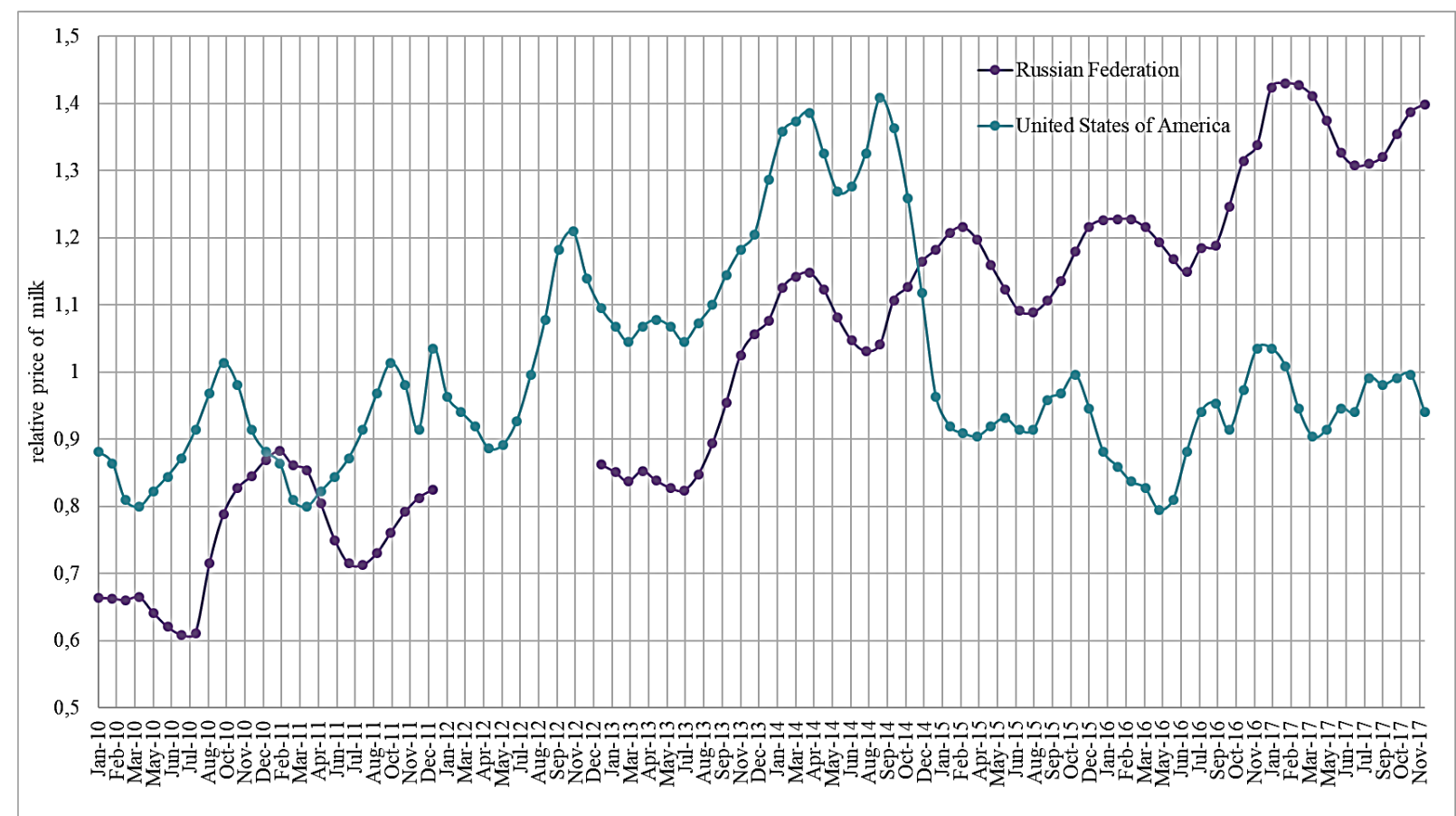

Fig. 2. Average monthly prices of milk for 2010-2017 in different countries, calculated by dividing by average values

In turn, the Irkutsk region belongs to the zone of risky agriculture (sharply continental climate) with dry summers and harsh winters, so the production and sale of agricultural products in the region depends greatly on climatic parameters. Moreover, both prices for crop and livestock products depend on the climate, as in the autumn-winter period there is a mass slaughter of livestock and the price of meat is reduced. In addition to climatic conditions, prices are also influenced by the import of products from other regions and countries.

The analysis of average monthly prices calculated relative to the initial value (by dividing the price for each month by the price for January 2012) shows that prices tend to grow, which is primarily due to inflation (see Fig. 3a and 3b). The price of legumes in June 2016 compared to January 2012 tripled, the price of seeds of perennial grasses for hay, potatoes and wheat in some months of the study period increased more than 2 times. However, the value of the relative price of pork in live weight changed slightly. Attention is drawn to the fact that the spread of average monthly potato prices increases annually. In addition, there is a seasonal wave, for the prices of legumes, potatoes, seeds of perennial grasses for hay, it is clear, and for wheat - not pronounced. This fact is explained by the fact that wheat prices are formed, to a greater extent, on the basis of world market prices and depend on the availability of stocks.

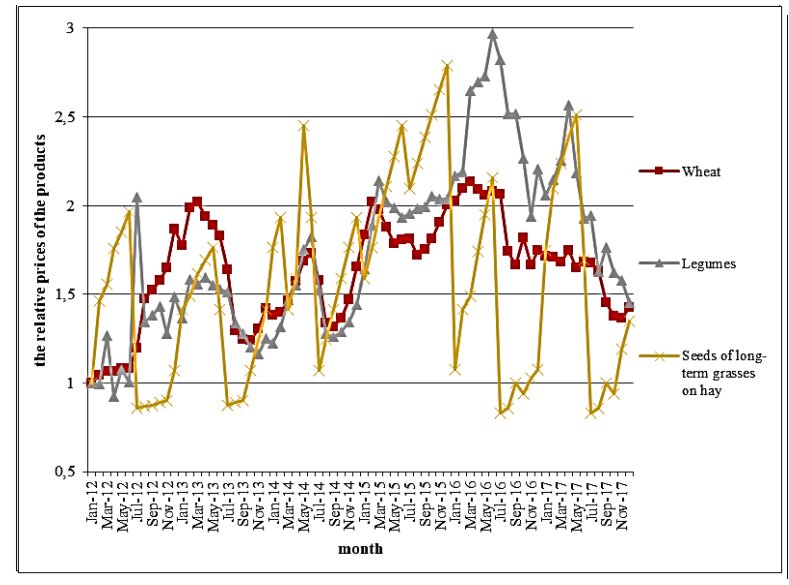

a)

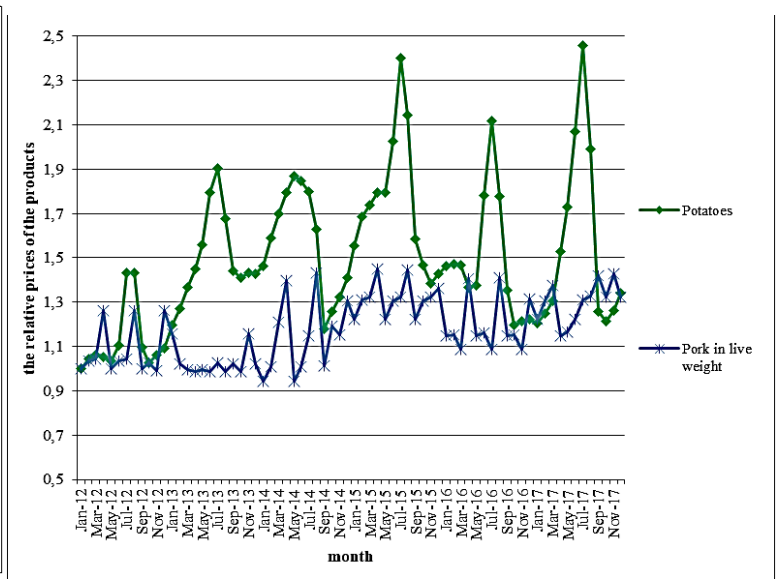

b)

Fig. 3. Variability of average monthly prices for agricultural products of the Irkutsk region for 2012-2017 relative to the initial value of the series: a) wheat, legumes, seeds of long-term grasses on hay; b) potatoes, pork in live weight 
B. Selection of the trend, seasonal component and residual component in the series of average monthly consumer prices in the Irkutsk region

To identify and assess the trend and seasonal component of long-term series in the works of different authors [9-14], various methods are proposed, taking into account the peculiarities of which the "Cassandra" model is created.

The equation of the model reflects the relationship between the actual value $x_{t}$ (a single series in a period of time $t$ ), with its three components: trend $y_{t}$, seasonal fluctuations $s_{t}$, residual term $\varepsilon_{t}$.

In the case of additive coupling, the equation of the model is as follows [15]:

$$
x_{t}=y_{t}+s_{t}+\varepsilon_{t} \text {. }
$$

The trend is expressed in the form of a polynomial from time -

$$
y_{t}=\sum_{i=0}^{n} a_{i} t^{i}
$$

$s_{t}$-the seasonal component is represented by the sum of strictly periodic functions with weights $t^{i}$ :

$$
s_{t}=\sum_{i=0}^{m} s_{i}(t) t^{i}
$$

where $s_{0}(t)$ - the average value of seasonal fluctuations, and the functions $s_{i}(t), i>0$ determine the change in the shape and amplitude of seasonal fluctuations from the time specified by the Fourier series expansion

$$
s_{i}(t)=\sum_{j=1}^{K / 2} \alpha_{i j} \cos \frac{2 \pi j t}{K}+\sum_{j=1}^{K / 2-1} \beta_{i j} \sin \frac{2 \pi j t}{K}
$$

where $K$ - the number of observations of a number in a year ( $K=4$ at quarterly statistics, $K=12$ - at monthly).

To estimate the parameters of the model $a_{i j}, \alpha_{i j}$, $\beta_{i j j}$ the least squares method is used. At the same time, the weights of informativeness of the initial data are introduced into the minimized target function of the linear programming problem

$$
\sum_{t=1}^{T} b_{t} \varepsilon_{t}^{2} \rightarrow \min ,
$$

provided (1)-(3). Information weights $b_{t}$ are used to account for qualitative and structural changes in the analyzed series in the past, as well as to assess the impact of external factors. In the absence of data on external influences, it is advisable to use exponential weights that reflect the aging of data at a constant rate

$$
b_{t}=b^{\lambda t}
$$

where $b^{\lambda}$ is the rate of data aging.

Based on the method of mathematical model "Cassandra", the trends and seasonal components of prices for agricultural products produced and sold by JSC "Irkutsk seeds" of the Irkutsk region are identified.

According to the obtained seasonality indices, the decline in prices for wheat, legumes and seeds of perennial grasses for hay occurs in the spring, during sowing (see Fig. 4).

The largest increase in the price of pork in live weight occurs in December and January, and the decline - in July. Potatoes become cheaper during the harvest period, from August to October (see Fig. 5).

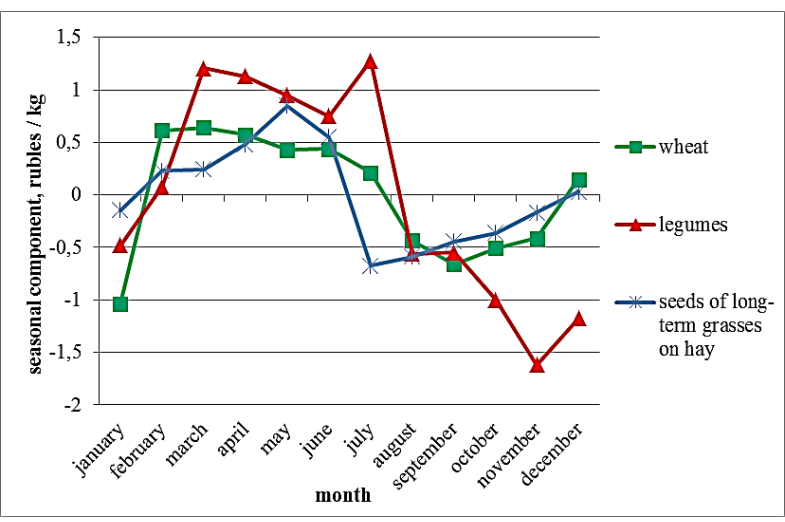

Fig. 4. The seasonal component of the monthly average prices of legumes, wheat, and seeds of long-term grasses on hay over the years 2003-2017.

Trend models taking into account the seasonal component, calculated on the basis of the "Cassandra" model, according to the Fisher criterion are accurate. The adequacy of the models was tested by analyzing a number of residual components. In addition, the coefficients of the trend equation according to the student's criterion are significant.

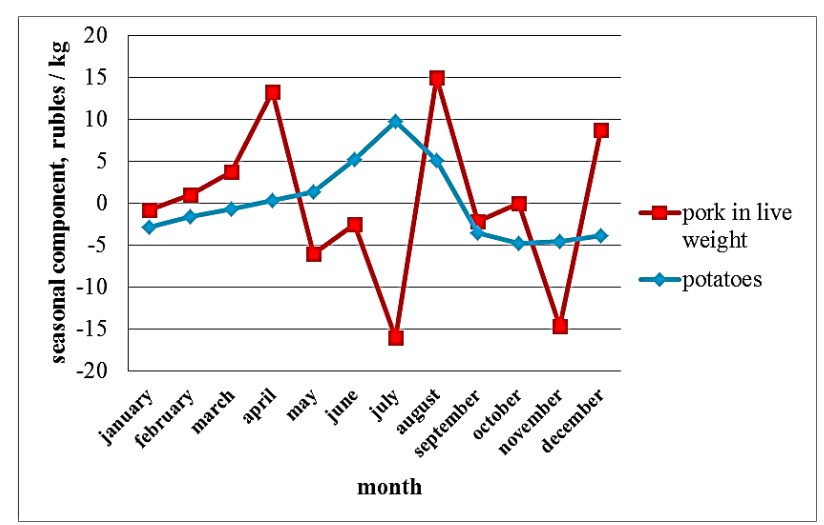

Fig. 5. The seasonal component of the monthly average prices of pork in live weight and potatoes of long-term grasses on hay over the years 2003-2017. 
The relationship between the components of the model is additive. Thus, the obtained models are suitable for forecasting prices in the short term, since the duration of the series under study is short. The values of the forecast of prices for agricultural products obtained using trend models taking into account the seasonal component for 2018 are given in table 1 .

\section{The use of forecast values of prices in the planning of agricultural production}

The obtained values of prices for agricultural products for 2018 are applied to solve the problem of optimizing the structure of agricultural production on the example of the agricultural enterprise JSC "Irkutsk seeds" of the Irkutsk region. The target function is focused on maximizing profits. Since the values of the coefficients of the objective function change in different months, the problem was solved many times.

TABLE I. PROJECTED PRICES FOR AGRICULTURAL PRODUCTS IN THE IRKUTSK REGION FOR 2018, RUBLES PER TON

\begin{tabular}{|c|c|c|c|c|c|}
\hline \multirow[b]{2}{*}{ Month } & \multicolumn{5}{|c|}{ Product } \\
\hline & Wheat & Legumes & Potatoes & $\begin{array}{c}\text { Seeds } \\
\text { of } \\
\text { long- } \\
\text { term } \\
\text { grasses } \\
\text { on hay } \\
\end{array}$ & $\begin{array}{c}\text { Pork in } \\
\quad \text { live } \\
\text { weight }\end{array}$ \\
\hline January & 7922,6 & 13830,0 & 28990,6 & 2299,0 & 117114,3 \\
\hline February & 9608,3 & 14490,4 & 30333,8 & 3088,6 & 127761,0 \\
\hline March & 9669,9 & 15721,6 & 31355,4 & 3234,3 & 133614,0 \\
\hline April & 9636,8 & 15745,5 & 32468,7 & 3758,0 & 140761,9 \\
\hline May & 9527,7 & 15664,2 & 33623,7 & 4472,5 & 110453,4 \\
\hline June & 9571,0 & 15569,5 & 37588,6 & 3557,6 & 119574,5 \\
\hline July & 9383,6 & 16197,7 & 42251,9 & 1016,7 & 125445,2 \\
\hline August & 8772,2 & 14460,2 & 37663,5 & 1212,0 & 154119,8 \\
\hline September & 8578,7 & 14572,1 & 29105,1 & 1660,7 & 130937,1 \\
\hline October & 8766,3 & 14224,0 & 28031,7 & 1670,7 & 129980,9 \\
\hline November & 8897,4 & 13704,3 & 28358,3 & 2196,4 & 134999,1 \\
\hline December & 9495,7 & 14248,1 & 29141,6 & 2535,4 & 140057,8 \\
\hline
\end{tabular}

According to the calculations given in table 2, the lowest profit from the production of agricultural products will be obtained by the enterprise when selling the products in October and will amount to 322.9 million rubles. The result is due to the fact that the enterprise in question is mainly engaged in the cultivation and sale of potatoes, the price of which in October is minimal. In addition, the prices for the rest of the products sold by Irkutsk seeds CJSC this month are also not high.

The maximum prices for products, according to the forecast, formed in July for potatoes and legumes, which led to the largest value of the target function in the implementation of all products this month (470.5 million rubles). At the same time, the volume of wheat production has significantly decreased and the volume of potato production has increased. At the same time it is necessary to understand that storage of the made production involves not only additional costs, but also losses from damage of production. Therefore, when solving the optimization problem it is necessary to introduce additional restrictions. In addition, there is a risk that the price in the planned month of sale of the goods will be much lower than the manufacturer expected. According to the results of calculations for the average annual prices for 2018, revenue will be about 368 million rubles. This decision can be guided in the case of sales of products at average annual prices. For example, the sale of part of the product immediately after production at low prices, and the preservation of a certain amount of goods to increase prices.

\section{CONCLUSION}

The paper analyzes the price trends for different agricultural products from different countries. It is revealed that the prices for the products considered in the work behave differently: in some cases chaotically, in others - have a clear seasonal wave, in the third - there are minor variations during the study period. 
TABLE II. THE RESULTS OF SOLVING THE PROBLEM OF PARAMETRIC PROGRAMMING FOR JSC "IRKUTSK SEEDS", TAKING INTO ACCOUNT THE FORECAST PRICES FOR THE MONTHS OF 2018

\begin{tabular}{|c|c|c|c|c|}
\hline \multirow[b]{2}{*}{$\begin{array}{l}\text { Type of } \\
\text { product }\end{array}$} & \multicolumn{4}{|c|}{ Production volume } \\
\hline & $\begin{array}{l}\text { at the } \\
\text { highest } \\
\text { profit }\end{array}$ & $\begin{array}{l}\text { at the } \\
\text { lowest } \\
\text { profit }\end{array}$ & $\begin{array}{c}\text { when } \\
\text { sold at } \\
\text { average } \\
\text { annual } \\
\text { prices }\end{array}$ & $\begin{array}{c}\text { according } \\
\text { to actual } \\
\text { data* }^{*}\end{array}$ \\
\hline $\begin{array}{l}\text { Wheat, c } \\
\left(x_{1}\right)\end{array}$ & 23000 & 32920 & 23000 & 23454 \\
\hline $\begin{array}{l}\text { Legumes, } \\
\mathrm{c}\left(x_{2}\right)\end{array}$ & 4153 & 4153 & 4154 & 4154 \\
\hline $\begin{array}{l}\text { Potatoes, } \\
\mathrm{c}\left(x_{3}\right)\end{array}$ & 102978 & 100149 & 102978 & 77840 \\
\hline $\begin{array}{l}\text { Seeds of } \\
\text { long- } \\
\text { term } \\
\text { grasses } \\
\text { on hay, c } \\
\left(x_{4}\right)\end{array}$ & 200 & 200 & 200 & 450 \\
\hline $\begin{array}{l}\text { Pork in } \\
\text { live } \\
\text { weight, c } \\
\left(x_{5}\right)\end{array}$ & 565 & 565 & 565 & 800 \\
\hline $\begin{array}{l}\text { Profit, } \\
\text { million } \\
\text { rubles }\end{array}$ & 470.5 & 322.9 & 368.4 & 266.4 \\
\hline
\end{tabular}

Analysis of the average monthly consumer prices of the Irkutsk region showed that in the longterm series there is a tendency of growth, while the growth rate, depending on the type of product, is different.

"Cassandra" model was used to identify and assess the trend, seasonal component and residual member of average monthly prices. Seasonality indices reflect the rise in prices for wheat, legumes and seeds of perennial grasses for seeds in the spring, potatoes - from January to July, pork in a living place - from February to April, in August and December.

Besides, trend models of forecasting average monthly consumer prices from seasonal fluctuations are constructed. The obtained models are used to predict the studied parameter for 2018. Since there are currently no statistical data for 2018, it is impossible to make a retrospective forecast and calculate the deviation of the actual data from the forecast. Taking into account the predicted values of prices, the problem of parametric programming for the planning of agricultural production on the example of JSC "Irkutsk seeds" of the Irkutsk region is solved. Since the enterprise in question is more focused on the production and sale of potatoes, the maximum profit, according to calculations, will be obtained when selling products in July, and the minimum - in October.

The proposed problem of agricultural production management can be used to build a plan of marketing activities and in the planning of agricultural production. In addition, taking into account the optimal timing of sales at the most favorable prices will certainly bring more income to agricultural producers and will give the opportunity to sell products with the best economic effect. It should be noted that such studies should be regularly conducted by the Ministry of agriculture of the region in order to create recommendations for agricultural producers.

\section{ACKNOWLEDGMENT}

The some results study was obtained with funded by RFBR according to the research project no. 19-07-00322

\section{REFERENCES}

[1] Z. Ma, R. Xu, and X. Dong World oil prices and agricultural commodity prices: The evidence from China. Agric. Econ., Czech, 2015, no. 61, pp. 564-576.

[2] A. I. Mikhailushkin. International economy, Moscow: Higher school, 2007.

[3] Y. C. Wang The optimal capital structure in agricultural cooperatives under the revolving fund cycles. Agric. Econ., Czech, 2016, no. 62, pp. 45-50.

[4] V. I. Zorkaltsev, I. V. Mokriy. The choice of the start date of the economic year according to the criterion of minimizing the amplitude of seasonal fluctuations. News of the Irkutsk State University, Series: Mathematics, 2017. vol. 22. pp. 50-62.

[5] V. I. Zorkaltsev, M. N. Polkovskaya, and N. I. Fedurina. Modeling of seasonal fluctuations in prices for agricultural products. Topical issues of agrarian science, 2018 , no. 28 , pp. 48-56.

[6] O. B. Filippova World market of agricultural raw materials and food, St. Petersburg, VNIK, 2008.

[7] Place of agriculture in the Russian economy, https://agrovesti.net/lib/industries/mesto-selskogokhozyajstva-v-ekonomike-rossii.html, last accessed 2019/02/01

[8] Producer prices by month, http://www.fao.org/faostat/ru/\#data/PM FAOSTAT, last accessed 2019/02/01

[9] J. Box, G. Jenkins. Time series Analysis: Forecast and management, Moscow, Mir, 1974.

[10] E. M. Chetyrkin. Statistical methods of forecasting, Moscow, Statistics, 1977 
[11] A. I. Goldstein. Theoretical development of the issues of calculating seasonal changes and a new method of calculating them. Works of the conjuncture institute, 1929, vol. 1, pp. 19-33.

[12] K. Granger, M. Hatanaka Spectral analysis of time series in Economics, Moscow, Statistics, 1972.

[13] R. C. Henshaw. Application of the general linear model to seasonal adjustment of economic time series. Econometrica, 1966, vol. 34, pp. 381-395.

[14] M. C. Lovell. Seasonal adjustment of economic time series and multiple regression analysis. J. of Amer. Statist. Assoc., 1963, vol. 58, pp. 993-1010.

[15] J. E. Floyd. Statistics for economists: a beginning. Toronto, University of Toronto, 2010. 